\title{
Motivação no Ensino Superior Estratégias e Desafios
}

\section{Êmila Silveira de Oliveira ${ }^{1}$}

\begin{abstract}
Resumo:
0 processo de educação é necessário na formação dos indivíduos. Por meio dele objetiva-se contribuir com a formação de sujeitos autônomos, críticos, criativos e ativos na sociedade em que vivem. Ao contrário do que pensamos, os conhecidos problemas educacionais do nosso país não estão restritos apenas à Educação Básica e podem ser facilmente visualizados também no Ensino Superior. Assim sendo, a partir da necessidade de se conhecer, debater e colocar em prática estratégias que contribuam com a melhora da qualidade de ensino e da aprendizagem no Ensino Superior no Brasil, esse trabalho teve por objetivo discutir a respeito da utilização da motivação como estratégia fundamental para a efetivação da aprendizagem de acadêmicos. Além disso, buscou-se entender as principais teorias motivacionais e a sua relação com a aprendizagem, conhecer o papel do professor no Ensino Superior e, mediante a compreensão da importância da atuação desse profissional, estabelecer estratégias de ensino e de motivação que auxiliem no aprendizado de graduandos.
\end{abstract}

Palavras-chave: Ensino. Aprendizagem. Formação docente.

\section{MOTIVATION IN HIGHER EDUCATION: \\ Challenges and Strategies}

\begin{abstract}
:
The education process is necessary in the formation of individuals, through it, the objective is to contribute to the formation of autonomous individuals, critical, creative and active in the society in which they live. Contrary to what we think, known educational problems of our country, are not restricted only to basic education and also can be easily viewed on Higher Education. Therefore, from the need to meet, discuss and implement teaching strategies that contribute to improving the quality of teaching and learning in higher education in Brazil,
\end{abstract}

1 Mestranda em Ciências Biológicas pela Universidade Federal do Pampa - Campus São Gabriel. emila-silveira@hotmail.com 
this study aimed to discuss about the use of motivation as key strategy for effective learning academics as well as understand the main motivational theories and their relationship to learning, meet the teacher's role in higher education and, by understanding the importance of the performance of this professional, establish teaching strategies and motivation to assist in undergraduate learning.

Keywords: Teaching. Learning. Teacher training. 


\section{Introdução}

O aprendizado por meio da educação é necessário no processo de formação dos indivíduos para que, mediante esse processo, esses indivíduos sejam capazes de desempenhar atividades no mercado de trabalho, conviver em família e nos demais grupos sociais. Por meio da educação objetiva-se contribuir com a formação de indivíduos autônomos, críticos, criativos e ativos na sociedade em que vivem.

Atualmente há uma grande preocupação e discussão com a qualidade do ensino brasileiro e com os grandes índices de evasão, violência, desinteresse e reprovação escolar.

Psicólogos, pedagogos, psicopedagogos, sociólogos, bem como órgãos relacionados à educação, que mediante estudos e implantação de novas propostas pedagógicas, têm procurado verificar os fatores que interferem no sucesso escolar dos alunos, visando melhorar a atual situação do ensino nacional (NEVES; BORUCHOVITCH, 2004, p. 77).

Estudiosos de diversas áreas relacionadas à educação tentam entender e desenvolver teorias e estratégias que contribuam para a melhoria do ensino brasileiro. E, ao contrário do que pensamos, os conhecidos problemas educacionais do nosso país não estão restritos apenas à Educação Básica e podem ser facilmente visualizados também no Ensino Superior.

"É generalizada a queixa de professores universitários a respeito da falta de interesse e dedicação aos estudos de seus alunos" (BARTALO; GUIMARAES, 2008, p. 2). Muitos docentes do Ensino Superior queixam-se da grande maioria de acadêmicos que agem como alunos passivos, demonstrando pouco interesse e rendimento universitário abaixo do esperado.

Embora haja essa carência de interesse e rendimento por grande parte dos universitários, são identificados também déficits em relação à qualidade de ensino e de aprendizagem, de um modo geral, nos cursos superiores. Segundo Ruiz (2004, p. 173), "Não há uma preocupação em conservar a motivação do universitário e tampouco em diminuir as dificuldades de aprendizagem”. 
Por muito tempo acreditou-se que para ser um bom professor universitário bastava apenas ter um profundo conhecimento na área de atuação desse profissional. E, por se tratar de um ensino de jovens e adultos, não seria necessário que esse processo de ensino fosse realizado de forma contextualizada e didática.

Autores como Fialho (2007, p. 16), afirmam que "a falta de motivação é a principal causa do desinteresse dos alunos", o que leva a um baixo desempenho de estudantes ao longo da sua Graduação, constituindo esta um fator determinante da qualidade do ensino e da aprendizagem. Considerando a falta de motivação um fator agravante na qualidade da aprendizagem, ao longo de vários estudos, tentou-se traçar alguns dos principais fatores que contribuem com a falta de motivação em alunos no Ensino Superior como, por exemplo: 1) A falta de interesse pelo aprendizado do curso, objetivando apenas a obtenção de um diploma; 2) O descobrimento tardio de que o curso escolhido não é a profissão que o indivíduo quer seguir futuramente; 3) O estudo é realizado apenas por fatores extrínsecos: provas e trabalhos e o almejo apenas da nota; $\mathrm{E}$, um dos fatores mais comuns e que ocorre principalmente com graduandos de cursos noturnos: 4) O fato de o aluno trabalhar e não ter tempo de dedicar-se totalmente aos estudos.

"A motivação no contexto escolar tem sido avaliada como um determinante crítico do nível e da qualidade da aprendizagem e do desempenho escolar" (GUIMARÃES; BORUCHOVITCH, 2004, p. 143). Pela motivação o professor pode influenciar a maneira como o aluno utiliza suas potencialidades, além de afetar positivamente a forma como esse aluno pensa e se desenvolve. Então, é necessário que esse professor consiga estabelecer estratégias de ensino para acadêmicos de Ensino Superior que atendam à demanda necessária para o seu aprendizado.

Para a composição desse trabalho foi realizada uma sucinta revisão bibliográfica sobre o tema na literatura específica, sendo consultados artigos e livros que pudessem subsidiar a discussão sobre o tema aqui exposto. Assim, a partir da necessidade de se conhecer, debater e colocar em prática estratégias de ensino que contribuam com a melhora da qualidade de ensino e da aprendizagem no Ensino Superior no Brasil, este trabalho teve por objetivo discutir a respeito 
da utilização da motivação como estratégia fundamental para a efetivação da aprendizagem de acadêmicos, bem como compreender as principais teorias motivacionais e a sua relação com a aprendizagem, conhecer o papel do professor no Ensino Superior e, mediante a compreensão da importância da atuação desse profissional, estabelecer estratégias de ensino e de motivação que auxiliem no aprendizado de graduandos.

\section{Desenvolvimento}

\section{Motivação e Aprendizagem}

O significado etimológico da palavra motivo - motivação - foi extraído do latim movere, motum, e significa aquilo que faz mover. Desta forma podemos relacionar motivar a modificar, mudar, impulsionar, estar em movimento, rumar para um objetivo a ser alcançado.

Podemos assim compreender a motivação, de um modo geral, como aquilo que impele uma pessoa a ter determinado comportamento ou atitude e, no mesmo sentido, empreender uma ação diante de determinada situação ou circunstância. Por meio da motivação o indivíduo é estimulado a desenvolver determinada tarefa. Uma tarefa para a qual se tem um "motivo", uma motivação em realizá-la, tem sua efetivação mais correta e desempenho diferenciado de uma tarefa realizada sem incentivo.

Alguns teóricos da aprendizagem defendem que a motivação é um dos principais fatores que contribuem e que devem ser utilizados no processo de ensino e de aprendizagem. No quadro a seguir podemos entender, resumidamente, a percepção de motivação, de três grandes conhecidos contribuintes das teorias da aprendizagem. 
Quadro 1 - Quadro comparativo da ideia de motivação na concepção de Piaget, Vygotsky e Ausubel

\begin{tabular}{|c|l|}
\hline Pensador & \multicolumn{1}{|c|}{ Definição para "Motivação" } \\
\hline PIAGET & $\begin{array}{l}\text { "Éa a procura por respostas quando a pessoa está diante de uma situação que ainda } \\
\text { não consegue resolver. A aprendizagem ocorre na relação entre o que ela sabe e o } \\
\text { que o meio físico e social oferece. Sem desafios, não há por que buscar soluções. } \\
\text { Por outro lado, se a questão for distante do que se sabe, não são possiveis novas } \\
\text { sínteses." }\end{array}$ \\
\hline VYGOTSKY & $\begin{array}{l}\text { "A cognição tem origem na motivação. Mas ela não brota espontaneamente, como se } \\
\text { existissem algumas crianças com vontade - e naturalmente motivadas - e outras sem. } \\
\text { Esse impulso para agir em direção a algo é também culturalmente modulado. O } \\
\text { sujeito aprende a direcioná-lo para aquilo que quer, como estudar." }\end{array}$ \\
\hline AUSUBEL & $\begin{array}{l}\text { "Essa disposição está diretamente relacionada às emoções suscitadas pelo contexto. } \\
\text { O prazer, mais do que estar na situação de ensino ou mediação, pode fazer parte do } \\
\text { próprio ato de aprender. Trata-se da sensação boa que a pessoa tem quando se } \\
\text { percebe capaz de explicar certo fenômeno ou de vencer um desafio usando apenas o } \\
\text { que já sabe. Com isso, acaba motivada para continuar aprendendo sobre o tema." }\end{array}$ \\
\hline
\end{tabular}

Fonte: NOVA ESCOLA, 2012.

Como podemos observar no quadro, diferentes teóricos apostam na mesma estratégia de ensino, a motivação. Piaget defende a motivação como o instrumento de instigar o aluno a solucionar os desafios propostos pelo professor. O professor, para Piaget, portanto, deve estabelecer desafios que motivem seus alunos a solucioná-los. Vygotsky, como os demais, acredita que um aluno motivado terá um rendimento melhor do que um aluno não motivado. A motivação seria a chave para o aprendizado; por meio dela os conteúdos seriam mais bem compreendidos. Ausubel atribui à motivação o interesse de conseguir realizar determinada tarefa e o aprendizado que se criou por intermédio dessa realização.

A importância da motivação no âmbito escolar tem sido reforçada e admitido o seu estudo por parte do educador. Assim, cabe principalmente ao docente criar estratégias de ensino que consigam motivar o aprendizado de seus alunos e trazer situações motivacionais nas diversas atividades de ensino.

Como já mencionado anteriormente, a motivação é a chave para um bom aprendizado. Quando o aluno está motivado no desenvolvimento de determinada tarefa, além de um aprendizado mais eficaz, esse aprendizado torna-se mais lúdico e prazeroso, criando um ambiente mais agradável e propício à aprendizagem. As autoras Davis e Oliveira (1994, p. 85) afirmam que "Uma pessoa 
motivada para aprender constrói o conhecimento mais prontamente do que uma sem motivação. [...] Um dos trabalhos mais importantes a serem desenvolvidos pelo professor junto aos seus alunos é, portanto, motivá-los”.

Embora muitos docentes de Ensino Superior acreditem que nessa modalidade de ensino não se faz necessário desenvolver estratégias motivadoras, muitos autores defendem que da mesma forma que é necessário um olhar diferenciado na Educação Básica, esse olhar deve ser utilizado também nas Universidades, pois tanto quanto nas demais instâncias de ensino, o Ensino Superior também objetiva o processo de ensino e aprendizagem, formando profissionais que atuarão ativamente na sociedade. Por isso, é necessário que a motivação possa ser encontrada em todas as tarefas realizadas pelo indivíduo, pois é ela que determina o grau de realização, persistência e efetivação do seu cumprimento.

A motivação e a aprendizagem no contexto escolar devem ser efetivas, constantes e ter propósitos bem definidos. Por meio delas a garantia de aprendizagem se eleva. Podemos afirmar que a aprendizagem e a motivação são dois fatores interligados. O não cumprimento de uma acarreta a não efetivação da outra. A partir disso, é necessário que ambas sejam encontradas no ambiente escolar, para que, pela motivação, tenhamos uma efetiva e real aprendizagem.

\section{Teorias Sociocognitivas da Motivação}

Mediante as teorias sociocognitivas da motivação para a aprendizagem, são classificadas duas orientações motivacionais que movem os indivíduos, ou seja, a Motivação Intrínseca e a Motivação Extrínseca.

A Motivação Intrínseca (ou autodeterminada) configura-se como uma tendência natural para buscar novidades e desafios. O indivíduo realiza atividades pelo próprio interesse. Por considerar prazeroso o desenvolvimento de tais atividades. "É uma orientação motivacional que tem por característica a autonomia do aluno e a autorregulação de sua aprendizagem" (NEVES; BORUCHOVITCH, 2004). 
A Motivação Extrínseca, por sua vez, tem sido definida como "a motivação para trabalhar em resposta a algo externo à tarefa" (NEVES; BORUCHOVITCH, 2004). Como, por exemplo, recompensas materiais ou emocionais que irão direcionar à realização de determinada atividade.

A ideia de o aluno ser motivado apenas pelos fatores intrínsecos e/ou extrínsecos foi substituída em 1980 pela Teoria da Autodeterminação (TAD) proposta pelos americanos Edward Deci e Richard Ryan. Por meio desta teoria pressupõe-se que todos os indivíduos são, por natureza, ativos e automotivados, curiosos, interessados, ansiosos pelo êxito. Cada indivíduo, no entanto, age de forma diferente em relação às suas interações com as pessoas, atividades e ambientes em decorrência da sua constituição interna e de suas necessidades psicológicas básicas, como a necessidade de autonomia, a de competência e a de pertencimento.

Por meio dessa Teoria presume-se que a motivação é mais complexa do que se pensa, e apenas fatores intrínsecos ou extrínsecos não são suficientes para atuar na motivação dos indivíduos, mas que entre esses fatores e a falta de motivação há um continuum da regulação, com quatro níveis de motivação extrínseca (Figura 1).

Figura 1 - Continuum da autodeterminação indicando os tipos de motivações, seus estilos regulatórios e o locus de causa
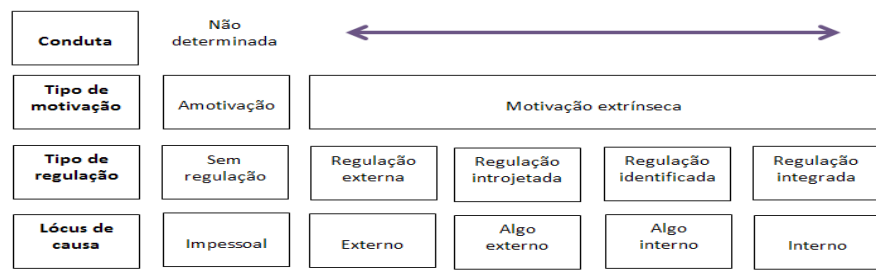

Autodeterminada
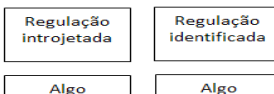

Regulação integrada
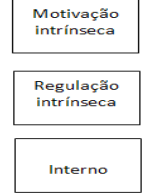

Fonte: DECI; RYAN, 2000.

No esquema de Deci e Ryan (2000), apresentado na Figura 1, podemos compreender de uma melhor forma o continuum que regula os tipos motivacionais, seus estilos regulatórios e os lócus da causa. A não motivação (amotivação, 
como citada pelos autores), como o próprio nome diz, refere-se à falta de motivação, à ausência de intenção ou de pensamento referente ao desenvolvimento de uma determinada atividade.

Podemos considerar a Regulação Externa como a forma mais básica da motivação extrínseca, designada como uma forma não autônoma de motivação (DECI; RYAN, 1985). Neste estilo, o desenvolvimento de uma tarefa se dará em decorrência dos fatores externos como premiações ou punições e não pelo prazer da sua realização.

$\mathrm{Na}$ Regulação Introjetada existe tanto um controle externo quanto uma situação de conflito interno que direcionam o comportamento do indivíduo e o impedem de realizar com êxito suas tarefas, como, por exemplo, a prevalência de culpa ou de ansiedade (STANDAGE; DUDA; NTOUMANIS, 2003).

Na Regulação Identificada os indivíduos visam se beneficiar com a atividade e não buscam satisfazer-se com a sua realização (NTOUMANIS, 2001).

Já a Regulação Integrada, é a forma mais autônoma da regulação externa do comportamento. Embora ainda haja interesse na obtenção de benefícios pessoais, há coerência nas ações e realização de escolhas pessoais (GUIMARÃES; BZUNECK, 2008).

Por fim, temos a Motivação Intrínseca ou Autodeterminada que é a melhor condição psicológica que o indivíduo pode apresentar, pois nesse estágio da motivação o indivíduo se reconhece como autor de suas ações e apresenta-se verdadeiramente engajado no desenvolvimento de uma atividade.

Em síntese, segundo a Teoria da Autodeterminação, a motivação não é "objetiva”, ou a pessoa é motivada ou não é motivada, mas sim é interligada com uma série de fatores internos e externos que condicionam e direcionam essa motivação considerando assim tipos qualitativamente diversos da motivação extrínseca, com efeitos diferenciados sobre os comportamentos.

Deci e Ryan (2000) distinguem ainda duas formas qualitativas da motivação, ou seja, a motivação autônoma e a motivação controlada (Figura 2). Cada uma delas é a combinação de ao menos duas formas de regulação, constantes do continuum. 
Figura 2 - Distinção da motivação autônoma e da motivação controlada

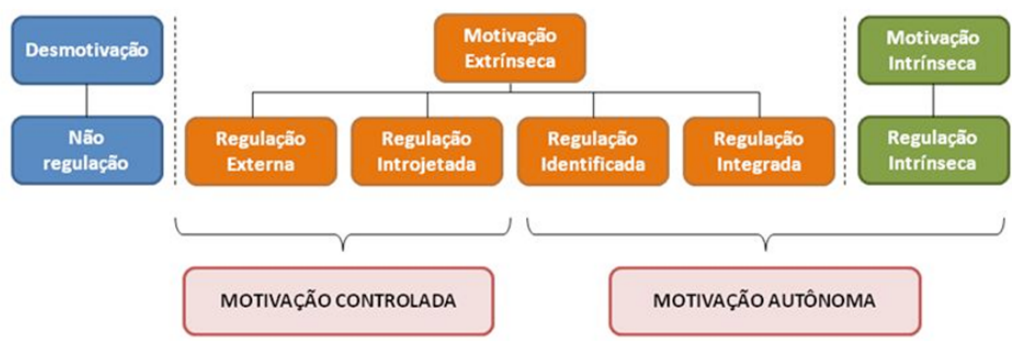

Fonte: DECI; RYAN, 2000.

A motivação autônoma engloba tanto a motivação intrínseca quanto as formas mais autorreguladas de motivação extrínseca, que são as motivações por regulação identificada e integrada. O comum entre elas é a característica do indivíduo apresentar prazer e interesse pela presença dos três componentes da autodeterminação: locus interno, liberdade psicológica e possibilidade de escolha.

O locus interno significa perceber que "o comportamento intencional teve origem e regulação pessoal, enquanto que o locus externo de causalidade se refere à percepção de ser uma 'marionete' frente às exigências externas" (DECHARMS, 1984).

A sensação de liberdade psicológica pode ser compreendida, segundo Rufini, Bzuneck e de Oliveira (2012, p. 54), como "a vontade de a pessoa executar um comportamento, quando ele é coerente e alinhado com os interesses, preferências e necessidades pessoais e não apresentado por obrigação ou por alguma forma de pressão". Por último, a percepção de escolha, segundo Deci e Ryan (2000), a qual "reflete a flexibilidade nas tomadas de decisão sobre o que fazer, como fazer ou até a possibilidade de não fazer".

De uma forma geral podemos afirmar que a motivação autônoma são as decisões e ações autônomas do indivíduo, atitudes por ele realizadas por conta própria, enquanto a motivação controlada é um comportamento regulado por variáveis externas, este menos eficaz do que o primeiro. E a forma como cada tipo de motivação é utilizado interfere diretamente no aprendizado. 


\section{Aprendizagem de Adultos}

Devemos levar em consideração que o público universitário em sua grande maioria é composto por adultos. Esses indivíduos acumularam ao longo de sua trajetória informações e experiências que devem ser utilizadas no processo de construção do conhecimento. O professor universitário necessita utilizar diferentes estratégias que motivem esses alunos a aprender e construir por meio de divergentes informações o seu próprio conhecimento.

"Para que as pessoas sintam-se intrinsecamente motivadas não há a necessidade de 'treino' ou 'instrução', isto pode ser influenciado pelas ações do professor e/ou instrutor, no contexto de seu local de ensino, que confia e se predispõe a utilizar determinadas estratégias que fomentem a motivação" (GUIMARÃES; BORUCHOVITCH, 2004, p. 80). Para isso o docente de Ensino Superior necessita conhecer como se dá a aprendizagem em adultos e saber como motivá-los e ensiná-los.

O indivíduo adulto já possui um acúmulo de experiências de vida e na maioria das vezes vê sentido naquilo que ele possa aplicar no seu dia a dia. Podemos afirmar que o processo educativo de um adulto ocorre e é baseado em características distintas do processo educativo de uma criança. Os adultos são indivíduos sensíveis a estímulos externos assim como as crianças, entretanto são fortemente condicionados por estímulos internos para a motivação e aprendizagem. A bagagem que ele já possui, a aplicação dessa aprendizagem no seu cotidiano e um "motivo" para aprender determinado conteúdo são fatores fundamentais para adultos se motivarem a aprender, não podendo sua aprendizagem ser centrada no professor, mas deve ser mediada e construída junto com este.

Algumas estratégias de aprendizagem podem ser incorporadas ao ensino de adultos para que haja uma melhor apropriação do conhecimento, como as Estratégias Cognitivas e as Estratégias Metacognitivas. Segundo Amaral (2007, p. 10), as Estratégias Cognitivas referem-se a:

Comportamentos e pensamentos que influenciam o processo de aprendizagem, de maneira que a informação possa ser armazenada com mais eficiência. Elas auxiliam a retenção e a utilização de novos conhecimentos; sua 
associação com conhecimentos prévios; o desenvolvimento e a reconstrução desses novos conhecimentos; bem como sua transferência para outros usos, situações e contextos.

Já as Estratégias Metacognitivas são procedimentos que o indivíduo adota para planejar, monitorar e regular o seu próprio pensamento.

A metacognição é, em termos simples, a consciência dos processos mentais que empregamos em um processo de aprendizagem, a capacidade de identificar as estratégias que utilizamos para promover uma aprendizagem mais duradoura e que leve a resultados mais eficazes. A consciência dessas estratégias e seu uso são essenciais para a utilização eficaz das estratégias cognitivas, como também para orientar e avaliar nosso progresso em relação aos objetivos traçados (AMARAL, 2007, p. 10).

Ainda segundo Amaral (2007, p. 11), são identificáveis cinco tipos de estratégias de aprendizagem para uma melhor organização do conhecimento em adultos:

1) Estratégias de Ensaio - referem-se a ação de repetir por meio verbal ou escrito o que se quer aprender;

2) Estratégias de Elaboração - quando estabelecemos relações entre o que aprendemos e as informações que já conhecemos sobre o assunto;

3) Estratégias de Organização - quando organizamos o material a ser estudado de forma que facilite seu aprendizado;

4) Estratégias de Monitoramento da Compreensão - quando tomamos consciência do que foi compreendido e o que não foi, e, a partir dessa compreensão, reorganizar novas estratégias de aprendizado.

5) Estratégias Afetivas - quando conseguimos controlar fatores emocionais e manter a atenção, desempenho e motivação.

Quando se tem conhecimento sobre estratégias para aprendizagem torna-se mais fácil a apropriação do conhecimento. Cada um deve experimentar diferentes estratégias para ver qual delas mais condiz com a sua personalidade e facilidade em aprender. E o docente de Ensino Superior também deve ter ciência da importância de estratégias de aprendizagem e deve também experimentá-las em suas aulas de modo que contribua com o aprendizado de seus alunos. 


\section{O Papel do Professor de Ensino Superior}

"Por um longo período prevaleceu no âmbito do Ensino Superior que para se capacitar um bom professor neste nível, necessário seria dispor de comunicação fluente e vasto conhecimentos relacionados à disciplina que pretendesse lecionar" (SILVA; BORBA, 2011, p. 3). Ainda hoje encontramos profissionais universitários que acreditam que não é necessário a utilização de recursos didáticos e aulas lúdicas no Ensino Superior, basta apenas possuir um excelente currículo que os alunos terão certamente um aprendizado eficaz.

Os professores preferem colocar a culpa no aluno pela não aprendizagem, do que assumir que pode ser sua culpa, e que uma simples mudança de método ou mesmo a sua didática pode fazer com que esse aluno aprenda. O professor que é dinâmico, pode sim mudar a maneira de o aluno encarar o processo ensino-aprendizagem, e ficar motivado a aprender, a querer mais e sentir-se feliz por aprender (ALVES, 2013, p. 33).

A forma como o docente ministra sua aula reflete-se na forma como os acadêmicos demonstram seu aprendizado. Uma simples mudança na estratégia de ensino pode contribuir significativamente para uma mudança também no aprendizado dos acadêmicos.

A aprendizagem de alunos jovens e adultos do Ensino Superior irá se construir em bases sólidas desde que, somados aos esforços pessoais dos alunos, seus professores também tragam uma vivência ou prática pedagógica embasada em referenciais teóricos nos quais eles acreditam e que estejam em sintonia com a filosofia da Instituição de Ensino Superior para a qual estes professores prestam serviços (GENCHINI, 2006, p. 22).

Temos ciência de que apenas um bom currículo não basta para se construir um processo de ensino e aprendizagem eficaz no ambiente universitário. É necessário que o docente entenda o processo de construção do conhecimento de jovens e adultos e como torná-lo eficiente. Todos os participantes do âmbito universitário devem estar comprometidos com a qualidade do ensino, porém recai sobre o docente a tarefa principal de estabelecer estratégias variadas de ensino que se comprometam com a efetivação da aprendizagem. 
Para Bartalo e Guimarães (2008, p. 1), "o desempenho acadêmico e a motivação de estudantes do ensino superior têm sido relacionados com o uso adequado de estratégias de estudo e de aprendizagem." O professor universitário necessita ter a ciência de que as estratégias (ou não estratégias) de ensino e motivação por ele adotadas influenciam diretamente no aprendizado de seus educandos.

São inúmeros os casos de desistência nos cursos superiores, pelos mais variados motivos. A falta de estímulos (internos e externos) para concluir a etapa da Graduação é um fator que merece bastante atenção. Bartalo e Guimarães (2008, p. 3) relatam que "é possível auxiliar os estudantes a se tornarem ativos, exercendo controle e refletindo a respeito da própria aprendizagem, por meio do ensino de estratégias de estudo e aprendizagem." O profissional comprometido com a aprendizagem faz com que seus alunos obtenham o conhecimento de uma forma prazerosa. O docente universitário, assim como os demais, necessita ter também um olhar diferenciado para esse processo e desenvolver estratégias que facilitem o entendimento do conteúdo, tornando-os próximos da realidade, úteis e práticos, atribuindo a eles um real significado.

Podemos considerar como uma das maiores dificuldades encontradas pelos professores nos dias atuais a dificuldade em motivar seus alunos e desenvolver estratégias de ensino que facilitem e estimulem o aprendizado por parte deles. Em meio à tecnologia disponibilizada na atualidade, o docente universitário não deve fugir dessa obrigação e também necessita adequar suas metodologias e didáticas para concretizar o processo formativo de seus alunos, adotando estilos significativos e eficazes de aprendizagem.

\section{Metodologias para a Motivação da Aprendizagem}

Para que haja uma mudança no ensino universitário, algumas modificações infraestruturais, curriculares e principalmente didáticas necessitam serem compreendidas e colocadas em prática nas Instituições de Ensino Superior em nosso país. É necessária uma estratégia que torne o processo de ensino mais eficaz e a utilização pelos docentes de estratégias de motivação que objetivem um real aprendizado pelos acadêmicos. 
Em decorrência da importância de se ter motivação na realização de tarefas de aprendizagem e da atuação primordial do professor universitário e o efeito que essa atuação causa na aprendizagem dos indivíduos, este tópico traz algumas sugestões de estratégias de ensino que podem ser aplicadas com o público universitário.

\section{Aulas expositivas dialogadas}

Podemos considerar a aula expositiva como uma das estratégias de ensino mais utilizadas e criticadas, caracterizada pela transmissão-recepção dos conteúdos, com o aluno sendo um sujeito passivo do conhecimento. As aulas expositivas dialogadas, por sua vez, podemos considerar como uma estratégia mais eficiente para o aprendizado dos alunos, pois elas possibilitam que estes interajam com o professor, contextualizando e construindo o conhecimento de uma forma coletiva.

Por meio de aulas expositivas dialogadas é possível que o professor estimule o cognitivo do aluno e articule com ele o processo de construção dos saberes. O ponto forte dessa estratégia é o diálogo entre o professor e o aluno, a participação ativa deste no decorrer das aulas e a construção mútua da aprendizagem.

\section{Aulas práticas}

As aulas práticas são excelentes condutoras da aprendizagem. Pela prática o professor consegue aproximar o conteúdo da vivência do aluno e fazer com que este visualize aquilo que está sendo estudado. Além disso, com as práticas os alunos deparam-se com resultados imprevistos e são desafiados a questioná-los, o que instiga sua imaginação e raciocínio.

As possibilidades de aprendizagem proporcionadas pelas atividades práticas dependem de como estas são propostas e desenvolvidas com os alunos. Atividades práticas que investiguem e questionem as idéias prévias dos educandos sobre determinados conceitos científicos podem favorecer a mudança conceitual, contribuindo para a construção de conceitos, embora 
este processo de mudança nem sempre ocorra no sujeito e existam diferentes acepções sobre a gênese e desenvolvimento conceitual (ANDRADE; MASSABNI, 2011, p. 841).

Embora aulas práticas sejam consideradas uma boa estratégia para a efetivação da aprendizagem, elas necessitam estar diretamente relacionadas com os conteúdos que estão sendo trabalhados, para que assim possam auxiliar num melhor entendimento da parte teórica e tenham um resultado eficaz no conhecimento.

\section{Discussão em grupo}

As discussões em grupo propiciam a participação de todos os indivíduos no processo de resolução de dúvidas e questionamentos, o que torna a busca pelas respostas um processo de aprendizagem mais interessante. Para Torres e Irala (2007, p. 61), a metodologia das discussões

têm o potencial de promover uma aprendizagem mais ativa por meio do estímulo ao pensamento crítico; ao desenvolvimento de capacidades de interação, negociação de informações e resolução de problemas e ao desenvolvimento da capacidade de auto-regulação do processo de ensino-aprendizagem.

Durante as discussões o aluno é direcionado a dar a sua opinião a respeito do assunto, concordando ou não com as demais, fazendo com que, assim, seja exposta uma gama de conceitos e concepções diferenciados que juntos constroem e organizam a temática ali discutida. A partir dessa metodologia o conhecimento pode ser construído de uma forma coletiva e a ele incorporados ideias e conceitos novos.

\section{Mapas conceituais}

Os mapas conceituais são uma estratégia de ensino que há pouco tempo começou a ser utilizada e vem ganhando cada vez mais espaço entre os recursos utilizados pelos docentes. Essa estratégia tem objetivos e características metodológicas fáceis de serem identificadas. O emprego de mapas conceituais 
incorpora novos conceitos à estrutura cognitiva do aluno e instiga esse aluno a refletir, pesquisar, selecionar e elaborar o conhecimento de uma forma diferenciada e significativa. Além disso,

os mapas conceituais são dinâmicos, pois à medida que o aluno desenvolve sua compreensão e o conhecimento sobre o assunto que está sendo trabalhado, os mapas devem ser revisados e retrabalhados para incorporar os novos conceitos (TORRES; MARRIOTT, 2007, p. 177).

Assim, o uso de mapas conceituais nas aulas constitui uma metodologia não fixa, ou seja, à medida que novos conhecimentos surgem, essas novas informações podem ser inseridas nesse mapa conceitual, fazendo com que o aluno visualize o esquema por ele formado e assim interprete de uma melhor forma a sua produção e conhecimento ali demonstrado. Por meio da construção de mapas conceituais o aluno é capaz de organizar o seu conhecimento, resumi-lo, revisá-lo, incorporar a ele novos conhecimentos e sistematizá-los com maior eficiência.

\section{Seminários}

Os seminários podem ser desenvolvidos individualmente ou em grupos e constituem uma estratégia de ensino e aprendizagem que possibilita uma boa aquisição de conhecimento.

A estratégia de apresentação por seminários pode ser utilizada para diferentes propósitos, entre eles a identificação de problemas; a análise de diferentes aspectos; a apresentação de informações relevantes; a recomendação de pesquisas essenciais para resolução de problemas; o acompanhamento do avanço das pesquisas; a apresentação de resultados aos membros do grupo; os comentários, críticas e sugestões dos colegas e do professor (UNIVERSIDADE..., 2013).

Por intermédio das pesquisas para a elaboração do seminário os alunos estimulam sua autonomia e se deparam com diversas informações que necessitam sintetizar e organizar. Desta forma, é possível que aprendam mais realizando a busca pelas informações e expondo-as posteriormente para os demais colegas e para o professor. 


\section{Utilização de TICs}

Consideramos a utilização das TICs como uma das mais importantes estratégias de ensino. Quando o aluno visualiza e interage com o que está estudando, torna-se mais fácil o entendimento daquilo com o que se está interagindo. O uso das Tecnologias de Informação e Comunicação (TICs) vem ocupando cada vez mais espaço entre as metodologias utilizadas em sala de aula. O uso dessas ferramentas torna as aulas mais atrativas, apoiando professores e alunos na construção do conhecimento.

As TICs apresentam-se sob diversas formas: Internet, softwares, jogos eletrônicos, blogs, recursos audiovisuais (RAVs), entre tantos outros. Com toda a tecnologia disponibilizada na atualidade é necessário que o docente a leve para dentro da sala de aula. Esses recursos diferenciados propiciam o acesso a diferentes informações que contribuem para o aprendizado dos educandos. Quando o aluno se sente motivado e atraído pela aula que o professor está ministrando, a aprendizagem acontecerá quase que instantaneamente e será incorporada ao indivíduo, por isso há a necessidade de o docente variar as suas metodologias e tentar fazer com que seus alunos tenham uma aprendizagem significativa.

\section{Considerações Finais}

O âmbito universitário, assim como as escolas, deve ser um espaço que motive e não que se ocupe apenas em transmitir conteúdos de forma não interativa. Para que isso ocorra o professor necessita ter um olhar diferenciado em relação ao ensino de jovens e adultos e à aprendizagem de seus acadêmicos. A formação pedagógica do docente de Ensino Superior é imprescindível para que ocorra uma melhora no ensino universitário.

Deve ser salientada a importância da motivação para os processos de aprendizagem. A motivação é a base para o sucesso. Cada um de nós aprende com maior facilidade conteúdos e contextos que despertam o nosso interesse. Quando o profissional levar para dentro das salas de aulas universitárias atividades contextualizadas, práticas e metodologias diversificadas, ele estimulará, interessará e motivará os seus alunos. O aluno "motivado" certamente estabe- 
lecerá uma relação de aprendizagem mais eficaz do que aquele que não possui motivação em aprender. Pela motivação os alunos são instigados a superarem os desafios e a concluírem as etapas necessárias para a sua formação.

A exploração do aspecto lúdico e metodologias mais didáticas no contexto universitário devem ser cada vez mais utilizadas. Recursos práticos e didáticos necessitam estarem presentes na maioria das situações de ensino, como um instrumento de apoio ao professor, para facilitar a explicação do conteúdo e o entendimento deste por parte dos alunos. Mediante esse olhar e atuação diferenciada no Ensino Superior as aulas tornar-se-ão mais atrativas e certamente oferecerão uma maior possibilidade de apropriação do conhecimento e, consequentemente, uma efetivação do aprendizado por parte dos acadêmicos, que terão uma formação mais significativa.

Devemos lembrar a grande responsabilidade dos docentes de cursos superiores na formação desses acadêmicos, afinal, direta ou indiretamente as suas ações se refletirão na sua formação. Acadêmicos que tiveram uma boa formação têm maior probabilidade de se tornarem profissionais que dominam sua área, competentes e dedicados, atuantes, ativos e íntegros na nossa sociedade.

\section{Referências}

ALVES, I. S. Motivação no contexto escolar: novos olhares. 2013, 55 f. Trabalho de Conclusão de Curso (Curso de Pedagogia) - Faculdade Capixaba da Serra, Serravix, Serra, ES, 2013.

AMARAL, V. L. Psicologia da educação. Natal, RN: EDUFRN, 2007. 208 p.

ANDRADE, M. L. F.; MASSABNI, V. G. O desenvolvimento de atividades práticas na escola: um desafio para os professores de ciências. Ciência e Educação, Bauru, v. 17, n. 4, p. 835-854, 2011.

BARTALO, L.; GUIMARÃES, S. É. R. Estratégias de estudo e aprendizagem de alunos universitários: um estudo exploratório. Informação e Informação, Londrina, v. 13, n. 2, p. 1-14, 2008.

DA SILVA, R. N.; BORBA, E. O. A importância da didática no Ensino Superior. 2011. 29p. Disponível em: <http://www.ice.edu.br/TNX/storage/webdisco/2011/11/10/outro s/75a110bfebd8a88958e5f511ca9bdf8c.pdf>. Acesso em: jan. 2016.

DAVIS, C.; OLIVEIRA, Z. Psicologia na educação. 2. ed. São Paulo, SP: Ed. Cortez, 1994. 
DECHARMS, R. Motivation enhancement in educational settings. In: AMES, C.; AMES, R. (Ed.). Research on motivation in education - student motivation. Nova York: Academic Press, 1984. p. 275-310. V. 1.

DECI, E. L.; RYAN, R. M. Intrinsic motivation and self-determination in human behavior. Nova York: Plenum, 1985.

. The "what" and "why" of goal pursuits: Human needs and the selfdetermination of behaviour. Psychological Inquiry, v. 11, n. 4, p. 227-268, 2000.

FIALHO, N. N. Jogos no ensino de química e biologia. Curitiba: Ibpex, 2007.

GENCHINI, E. B. O ensino superior no Brasil: fatores que interferem no rendimento escolar e a visão dos alunos sobre suas dificuldades de aprendizagem. Revista da Educação, v. I, n. 1, p. 18-30, 2006.

GUIMARÃES, S. É. R.; BORUCHOVITCH, E. O estilo motivacional do professor e a motivação intrínseca dos estudantes: uma perspectiva da teoria da autodeterminação. Psicologia: Reflexão e Crítica, v. 17, n. 2, p. 143-150, 2004.

GUIMARÃES, S. É. R.; BZUNECK, J. A. Propriedades psicométricas de um instrumento para avaliação da motivação de universitários. Ciências \& Cognição, v. 13, n. 1, p. 101-113, 2008.

NEVES, E. R. C.; BORUCHOVITCH, E. A motivação de alunos no contexto da progressão continuada. Psicologia: Teoria e Pesquisa, v. 20, n. 1, p. 77-85, 2004.

NTOUMANIS, N. A self-determination approach to the understanding of motivation in physical education. British Journal of Educational Psychology, v. 71, p. 225-242, 2001.

NOVA ESCOLA. Toda a atenção para a neurociência, Ed. 253, 2012. Disponível em: <https://novaescola.org.br/conteudo/217/neurociencia-aprendizagem>. Acesso em: 25 jan. 2016.

RUFINI, S. É.; BZUNECK, J. A.; DE OLIVEIRA, K. L. A qualidade da motivação em estudantes do Ensino Fundamental. Paidéia, Ribeirão Preto, v. 22, n. 51, 2012.

RUIZ, V. M. Estratégias motivacionais: estudo exploratório com universitários de um curso noturno de Administração. Psicologia Escolar e Educacional, v. 8, n. 2, 2004. Disponível em: <http://www.scielo.br/pdf/pee/v8n2/v8n2a05.pdf>. Acesso em: 23 jan. 2016.

SILVA, R. N; BORBA, E. O. A importância da didática no Ensino Superior. Instituto Cuiabano de Educação. Disponível em: <http://www.ice.edu.br/TNX/storage/webdisco/2011/11/10/outros/75a110bfebd8a88954e5f511ca9bdf8c.pdf $>$. Acesso em: 25 jan. 2016.

STANDAGE, M.; DUDA, J. L.; NTOUMANIS, N. A model of contextual motivation in physical education: using constructs from selfdetermination and achievement goal theories to predict physical activity intentions. Journal of Educational Psychology, v. 95 , n. 1, p. 97-110, 2003. 
TORRES, P. L.; MARRIOTT, R. de C. V. Mapas conceituais: uma ferramenta para a construção de uma cartografia do conhecimento. In: TORRES, P. L. (Org.). Algumas vias para entender o pensar e o agir. Curitiba: Senar-PR, p. 173-211, 2007.

TORRES, P. L; IRALA, E. A. Aprendizagem colaborativa. In: TORRES, P. L. (Org.). Algumas vias para entender o pensar e o agir. Curitiba: Senar, PR, 2007. p. 61-93.

UNIVERSIDADE NOVA DE LISBOA. Estratégias pedagógicas. Lisboa: Cadernos da Nova; Gabinete de Apoio à Qualidade do Ensino; Núcleo de Inovação Pedagógica e de Desenvolvimento Profissional dos Docentes, 2013.

Recebido em: 26/4/2016

Aceito em: 4/11/2016 